James L. Mullins, Frank R. Allen, and Jon R. Hufford

\title{
Top ten assumptions for the future of academic libraries and librarians A report from the ACRL research committee
}

I n 2006 the ACRL Executive Committee asked the ACRL Research Committee to determine ten assumptions about the future that would have a signi cant impact on academic libraries and librarians. In the ensuing months, members of the Research Committee reviewed previous similar reports; surveyed ACRL committees, councils, and sections; conducted literature reviews; and reviewed the ACRL Environmental Scan of 2003. What emerged was a long list of statements that, after deliberations, was shortened to the ten most pertinent assumptions. These assumptions identify present conditions that the committee feels will have a signi cant impact on how academic libraries and librarians plan for the next ten years.

The assumptions were unveiled at the ACRL 13th National Conference in late March and commented upon at a panel discussion by Pam Snelson (Franklin \& Marshall College), ACRL president; Julie Todaro (Austin Community College), ACRL president-elect; Sherrie Schmidt (Arizona State University), president, Association of Research Libraries (ARL); and Doug Lederman, coeditor, Inside Higher Ed. In order to obtain comments from attendees at the presentation, ACRL made a Web survey available.

Upon rst examination, the assumptions appear to be less than profound. Some readers might be looking for edgier future-oriented statements, but, as we know, the future is dif cult to predict. For example, some experts forecasted in the early 1990s that traditional universities would experience waves of closures in coming decades due to competition from online education providers and corporate in-house vocational training programs. Research library collections were anticipated to be reduced to the point where they would $t$ into a space the size of a thimble! The opposite has occurred on both accounts. Higher education, including academic libraries, has experienced robust virtual and physical growth, and the importance of research library collections only continues to increase.

So, as we stand in 2007 and look to the future, it is important to remember that instead of attempting to forecast, we are better off using the assumptions to encourage ACRL librarians to embrace the changes and opportunities that are already occurring and to build into their libraries a culture that will continue to embrace change and opportunities that the future will bring.

The committee acknowledges that there are nascent issues developing within the profession that have not reached the level of being recognized as trends or developed enough to be identi ed as assumptions. It is the expectation of the Research Committee that in response to the publication of this list, nascent areas will be identi ed and researched for their impact within the profession.

\section{Top ten assumptions (in ranked order)}

1. There will be an increased emphasis on digitizing collections, preserving digital archives, and improving methods of data storage and retrieval. Academic libraries have an opportunity to make their unique collections available

James L. Mullins is dean of libraries at Purdue University, e-mail:jmullins@purdue.edu; Frank R. Allen is associate director for administrative services at the University of Central Florida, e-mail: fallen@mail.ucf.edu; Jon R. Hufford is associate librarian at Texas Tech University, e-mail: jon.hufford@ttu.edu

(c) 2007 James L. Mullins, Frank R. Allen, and Jon R. Hufford 
to the world in unprecedented ways. In fact, the digitization of unique print collections may emerge as one of the primary missions of academic libraries in the 21st century. Librarians should collaborate with disciplinary colleagues in the curation of data as part of the research process.

2. The skill set for librarians will continue to evolve in response to the needs and expectations of the changing populations (students and faculty) that they serve. Changes in skill sets among library professionals are well underway. Entry level salaries are increasing, due in part to the increased expectations of a new generation of professionals who have other career options. The aging of the profession can be viewed as having a number of positive bene ts, for as retirements increase, new opportunities will open for a new generation of MLS librarians and other allied professionals. Libraries that are open to creating new career paths within their organizations are in an optimal position to embrace the future.

3. Students and faculty will increasingly demand faster and greater access to services. Statements such as print journals are to todays students what micro che was to the previous generation are becoming increasingly common.

\section{Seeking your reaction}

The Research Committee wants to know what you think. How does each assumption impact your library or you professionally? Are you aware of any developing issues or nascent trends that are not captured in the list? Reply online at https://marvin. foresightint.com/surveys/Tier1Survey /ACRL/156 by April 30, 2007.

Members of the 2006-07 ACRL Research Committee include:James L. Mullins (chair), Steven Adams, Frank Allen, Karyle Butcher, Rick Fought, Jon Hufford, Rebecca Jackson, Regina McBride, Kara Malenfant (ARCL staff liaison), Barbara Moran,Ashley Pillow, Richard Rubin, Kimberly Burke Sweetman, Ruth Vondracek, Tyler Walters, Jennifer Dorner (ex-officio) and Mark Emmons (ex-officio).
Similarly, the refrain print journal material is becoming invisible can be heard. What implications do information- seeking behaviors and attitudes have for the selection of materials, and in what format?

4. Debates about intellectual property will become increasingly common in higher education. While this is not a new issue, what is new is the increased opportunity for infringement upon intellectual property rights brought about by online access.

5. The demand for technology-related services will grow and require additional funding. The digital revolution is in its infancy; academic libraries are still operating in a predominantly print world. Futurists predict that both the supply and demand for print material will continue to increase in the near future, but a tipping point will inevitably occur. Tipping points are often followed by an abrupt decline in interest in outof-favor technologies. Consider: What library products and services will decline over the next ten years? Will libraries be able to reallocate resources into new technologies? Which products and services are already effectively dead, but are being kept on life support, hence are slowing efforts to embrace new technologies?

6. Higher education will increasingly view the institution as a business. Today, universities are extremely focused on fundraising and grant writing, maximizing revenue, reducing costs, and optimizing physical space. Do academic libraries have suf cient data to defend how their resources are allocated?

7. Students will increasingly view themselves as customers and consumers, expecting high-quality facilities and services. Today s students are increasingly paying the true cost of their education and demanding to be treated as customers. This has profound implications, ranging from how teaching faculty interrelate with students to the quality of residential housing and library facilities. Universities are becoming more aware of the importance of attractive library facilities as an effective recruitment tool. Is your library a strong advocate for high-quality, customer-friendly library facilities and services?

(continues on page 246) 
You want to make sure you are following all the local rules and procedures, especially if this material will be posted online for anyone to access.

5. Get training, or read the literature in your area. I have heard of many new librarians who were basically told where their of ce was, what their responsibilities were, and then left on their own. Even if you re given training and guidance, seek out other information. If there is one thing that most librarians do very well, it s documentation. There are tons of articles and books on every aspect of librarianship. Keep those ILL folks busy!

6. Read! Even beyond the literature in your area, read some of the basic journals of librarianship. Keep up on the current issues of the profession. If you re interested in issues about mentoring, achieving tenure, or writing for the profession, there are tons of articles and books to be found. Also look into local and regional publications. Even if you re not involved at this level, it can be bene cial to know what $s$ happening. And many of these publications are now online. Start Googling.

("Top ten ..." continued from page 241)

8. Distance learning will be an increasingly more common option in higher education, and will coexist but not threaten the traditional bricks-and-mortar model. Throughout higher education, technology has made possible the rapid proliferation of online instruction. The just-in-time model of imbedding library tutorials into Web-based courses complements traditional just-in-case library instruction, and may surpass it in the future. Libraries will want to continue to develop products and services that scale, i.e. are easily replicated, in an increasingly resource-stretched environment.

9. Free public access to information stemming from publicly funded research will continue to grow. This is perhaps the most unpredictable and exciting of the ten assumptions, and legislation will play a key role here. Finished research will still need to be vetted, edited, organized, and disseminated in logical ways. It could be advantageous for the academic community to return to the
7. Keep notes. In meetings, workshops, etc., take plenty of notes and keep them. You never know when you might need to refer to them. If you attend workshops, be sure to get contact information from the trainers, if possible, for follow-up questions.

8. Keep your résumé/curriculum vita up to date. Most likely, if you re new to your position, you re not looking for a new job. That doesn $t$ mean you can $t$ keep your records current. When I was last job hunting, I hadn $\mathrm{t}$ updated my $r$ sum in over seven years. Can you remember everything you did in the last seven years? I couldn t either. I have to submit my curriculum vita every year with my evaluation for my pretenure review, so I have a reason to keep it up. But even if you re not required to, I highly recommend it.

There are probably tons of things I ve missed that I could recommend for other new librarians, but these stand out to me as the most important.

If I had to pick the most important piece of advice, I would say When in doubt, ask someone! $\pi$

scholarly publication business if it can be proven to address the soaring cost of access to published scienti c research. Libraries could and should play a leading role, understanding that it may require reallocation of institutional resources.

10. Privacy will continue to be an important issue in librarianship. This is another assumption that has taken on greater attention and importance due to advances in technology. The debate becomes even more of an issue for libraries that are moving toward authentication and/or password access to electronic workstations located in public areas of the library.

The above assumptions underscore the dominant roles that technology and consumer expectations are increasingly playing in libraries. The trends underlying these assumptions offer new opportunities for those academic libraries and librarians who are ready and willing to embrace the future. That future is with us today and it is exciting! 2 